\title{
Saneamento das Cidades Brasileiras (*)
}

\author{
Geraldo Ferreira Sampaio \\ Engenheiro Civil pela Escola Politécnica \\ de São Paulo
}

C

ONVIDAdo pelo ilustre Diretor da Divisão de Edifícios Públicos do D.A.S.P., Sr. SindôRo CARNEIRO DE SouzA, para dizer algumas palavras sôbre a ação dos engenheiros brasileiros no saneamento de cidades, apesar de reconhecer as minhas dificuldades de expressão, aceitei, por julgar que estando eu há 44 anos em trabalho constante neste setor da engenharia nacional, tinha até mesmo o dever de dar um depoimento.

Estas trocas de idéias entre engenheiros, programadas pelo Sr. Diretor da Divisão, têm - acredito - o mesmo objetivo do que se está fazendo em França, de que tomei conhecimento ao ler a conferência do Sr. Engenheiro General PIERre SALmon, presidente da Sociedade dos Engenheiros Civis de França, realizada na Socièté Royale Belge des Engenieurs em 11 de outubro de 1961. Acha êle que os engenheiros sendo forçados - hoje em dia - a dedicarem longo tempo a uma especialidade, devem fazer esforços por se interessarem por outros assuntos e adquirir conhecimentos gerais, que lhe serão necessários quando êles, que constituem, sem dúvida, uma elite da nação, forem chamados a tomar parte na alta direção do país e na Política. E acrescenta: os chefes de emprêsas, desejosos de dispor de quadros tão cultos quanto possivel, têm favorecido a criação de escolas, de cursos, de centros, nos quais, por um tempo limitado, os engenheiros rossam se pôr ao corrente dos problemas da atualidade. Outras emprêsas, como solução prática, têm preferido recorrer ao sistema de conferências pronunciadas nos próprios locais de serviço, fora dos horários normais de trabalho.

Temos de reconhecer, assim, ser uma preocupação na França $o$ entrosamento de engenheiros lidando em setores diversos.

\section{INTRODUÇÃO}

Cumprindo o programa direi em primeiro lugar algo sôbre as cidades brasileiras, em seguida como tem agido o engenheiro para criar condições de higiene para as nossas aglomerações hu

(*) Conferência realizada na Divisão de Edifícios Públicos na série "Ciclo de Palestras na D.E.P. em 1962". 
manas e, depois, para finalizar, algumas observações que possam: ser úteis para as futuras atividades dos engenheiros que ora me ouvem.

\section{AS CIDADES BRASILEIRAS}

As cidades brasileiras formaram-se sem um plano estabelecido, seguindo, geralmente, as principais estradas. As ruas da maioria das nossas cidades, no Brasil central e no norte, foram estabelecidas em larguras diminutas, de 60 palmos, talvez com o fim de tê-las mais ensombradas e, portanto, menos aquecidas nos longos periodos de calor.

No sul do Brasil, no Rio Grande do Sul, ou por ter sido. habitado só a partir de 1715 e ter clima mais frio ou, talvez, pelo aspecto dos campos com horizontes amplos, geralmente, as: ruas das cidades foram estabelecidas com maiores larguras. Algumas foram traçadas no terreno por um técnico, na época um «pilôto da carta». Estas eram sempre em xadrez, tendo na parte central, ocupando quatro quarteirões, uma ampla praça onde eram localizados os edifícios do Culto e os da Administração. Estas cidades do Sul, assim traçadas, resultaram de uma antiga lei, que obrigava os donatários das terras nos principais "passos" (travessia de rios) a reservar uma superfície de 272 hectares para a formação de povoados.

Ainda hoje, as cidades do norte $e$ as do interior do país. apresentam o seu núcleo central com o caráter dos antigos tempos, pela arquitetura colonial revelada em templos católicos, edificios públicos e casas particulares. Os templos estavam sempre colocados em praças, cujo formato e tamanho eram os mais variados.

Em 1894 projeta-se e constrói-se, sob a direção de Aarão Reis, a primeira cidade, cuidando-se de fazer urbanismo. Assim criou-se Belo Horizonte, capital do Estado de Minas Gerais, hoje. com uma população superior a 690.000 habitantes. Em 1907, Saturnino de Brito projeta a expansão da cidade de Santos, o maior pôrto do pais, estabelecendo normas para o traçado sanitário das cidades. Em 1916 êstes principios básicos foram apresentados em Memória, "Le Tracé Sanitaire des Villes", no concurso para a reconstrução das cidades francesas destruídas pela guerra. Mais de cinqüenta municipios brasileiros aceitaram estas idéias e concretizaram-nas em projetos de expansão dos centros urbanos. Era o aproveitamento da topografia local no traçado das novas ruas, fazendo seguir pelos talvegues uma Avenida, rua ou viela, e fazendo as outras ruas cortarem as curvas de nivel do terreno normalmente. Ruas para o trânsito seriam estudadas, cortando estas para facilitar o acesso. Com êste traçado as linhas naturais de esgotamentos das águas eram mantidas, o 
que economizava na construção dos coletores de águas pluviais e de esgotos sanitários.

Em 1920, no Rio Grande do Sul, Carlos Torres Gonçalves projetou e logo depois foi construida, a cidade de Irai, estação de águas sulfurosas, adotando-se o programa de projetar as sedes dos núcleos coloniais. Já nos nossos dias, em 1934, surgiu mais uma cidade, projetada e construida para capital do Estado. de Goiás, e chamada Goiânia, hoje com 130.000 habitantes, e ùltimamente, a nova capital do pais: Brasilia.

As grandes cidades, como o Rio de Janeiro, São Paulo, Recife, Pôrto Alegre. Santos e várias outras, vêm-se desenvolvendo ràpidamente, criando bairros novos, abrindo novas avenidas $e$ apresentando já o aspecto comum dos grandes centros do mundo, aspecto internacional, que os novos materiais de construção e a arquitetura moderna imprimiram às cidades de hoje.

O censo de 1950 revelou a existência no nosso país de 1.890 municipios, com 1.887 cidades e 3.482 vilas ou sedes de distrito. Rio e São Paulo que em 1950 possuiam 2.400 .000 e 2.200 .000 habitantes respectivamente, têm hoje 3.300 .000 e 3.800 .000 , seguindo-se Recife com 800.000 , Salvador com 650.000 e Pôrto Alegre com 640.000, além de Belo Horizonte já referida. Em 1950 contava-se 1.000 núcleos de população com mais de 1.000 habitantes e em 1960 êste número elevou-se para 2.380. A Lei n' 311 de 1938 considerou população urbana todo agrupamento que servisse de sede a municipio ou a distrito. A sede do município deveria ter no minimo 200 casas e seria cidade, ao passo que a dos distritos deveria ter no mínimo 30 casas e seria vila. Foram, porém, mantidas, mesmo sem êstes minimos, as sedes dos municípios existentes como cidades e as dos distritos da época da lei, como vilas.

A "Conjuntura Econômica" de outubro de 1951, estudando a. urbanização no período intercensitário de 1940 a 1950 , concluiu que houve um aumento da população urbana sôbre a população total de $5,2 \%$, sendo em 1950 a população urbana $36,4 \%$ e a rural $63,6 \%$, tendo ocorrido uma migração do campo para as cidades. Em alguns Estados, como Paraná, Goiás e Santa Catarina houve, ao contrário, aumento da população rural. Conclui realçando que «não é oportuno discutir se isto foi um progresso ou se tal aumento incontestável na percentagem da nossa população urbana determinou uma diminuição da mão-de-obra disponivel nas atividades agrícolas do país, criando dificuldades".

A população urbana que em 1940 era de 12,8 milhões, passou em 1950 para 19,2 milhôes de habitantes e em 1960 , para 32.038.222, sendo o total do pais em 1950 de 52,6 milhões, c em 1960, de 70.263.000. A corrida do campo para as cidades acentuou-se, portanto, no último decênio. 
VioLitch no seu magnifico trabalho sôbre as cidades da América Latina em 1943 assim se exprimiu:

"Dois terços da América Latina está mal alojada a julgar pelas normas mínimas aceitas de espaço, luz e higiene".

E ainda:

"Conforme um cálculo feito, $75 \%$ dos habitantes da Capital do Brasil vivem em casas «sub-standard» e $60 \%$ em São Paulo. Estas habitações consistem de favelas, vilas, cortiços, construídos durante os mesmos anos da imigração européia que deu origem às «casas de cômodos" do bairro Este de Nova York".

As percentagens acima indicadas são, sem dúvida, exageradas, mas, sem falar nas casas com más condições de higiene, o Rio possuía, pelo Censo de 1950,58 favelas com 45.235 prédios e com 169.305 habitantes. Se contarmos os casebres, idênticos aos das favelas, mas situados em tôda a cidade, devemos, de acôrdo com os levantamentos do Serviço Nacional de Febre Amarela, contar com 90.000 casebres e pròximamente 340.000 pessoas. Mas, atualmente são 327 as favelas com 900.000 habitantes que somados aos moradores de casas de cômodos representarão cêrca de $1 / 3$ da população do Rio.

Estas populações na nossa "Cidade Maravilhosa" se acham sem a menor condição de higiene e se ainda lembrarmos como atualmente é precária a distribuição de água no Rio e que menos da metade das casas estão ligadas à rêde de esgotos, podemos concluir que as frases célebres de Miguel Pereira e Afrânio Peixoto - "Não nos esqueçamos que o Brasil é ainda um vasto hospital" e "O sertão começa na Avenida Central" - velhas de cinqüenta anos, são hoje ainda em parte, triste realidade.

\section{A ENGENHARIA SANITÁRIA E A OBRA DE SATURNINO DE BRITO}

Não se pode falar hoje no Brasil em saneamento das cidades sem lembrar Saturnino de Brito, falecido em 1929 e justamente cognominado "o médico das cidades".

Como se sabe, a moderna engenharia sanitária começou, realmente, em 1815, na Inglaterra, e desenvolveu-se em obras úteis após a epidemia de cólera de 1831. A primeira lei sanitária inglêsa data de 1848, estabelecendo os princípios do "water carriage", sendo que a partir de 1850 a orientação se define de modo preciso, principalmente depois que Baldwin Lathan, em 1873, publicou a primeira obra didática sôbre esgotos. O sistema geralmente adotado na Inglaterra tem sido o separador parcial. 
Nos Estados Unidos da América do Norte, em 1870, o coronel G. E. Waring organizou de modo metódico o sistema separador absoluto. Em nosso país foi Saturnino de Brito quem se bateu, desde 1898, pela adoção dêsse sistema, fazendo propaganda constante e eficiente e podendo ver em pouco seu pontode-vista inteiramente vitorioso, o que tornou fácil, às pequenas cidades como às grandes, a realização de obras básicas para sua salubridade.

Saturnino de Brito é considerado o mestre da engenharia sanitária no nosso país, tendo sido o seu nome citado e os seus trabalhos elogiados na França, na Inglaterra e nos Estados Unidos. A sua obra escrita é vasta, compondo-se de 23 volumes, de que o Ministério da Educação fêz tirar uma edição completa. Entre estas obras pode-se destacar como originais os relatórios sôbre o Saneamento de Santos, sôbre o Saneamento de Recife, sôbre Melhoramentos da Lagoa Rodrigo de Freitas, do rio Tieté, do rio Paraíba e Lagoa Feia e "Le Tracé sanitaire des Villes".

O valor do trabalho dêste grande engenheiro é o de ter sistematizado e organizado todos os detalhes necessários para a construção do saneamento de uma cidade, criando, pelos tipos simples de obras, uma verdadeira técnica sanitária brasileira.

O Professor Lourenço Baeta Neves, da Escola de Engenharia da Universidade de Minas Gerais, denominou a êste conjunto técnico "escola brasileira de engenharia sanitária", "escola brasileira de Saturnino de Brito".

Obedecendo inteiramente aos principios da Escola Brasileira já foram realizadas no Brasil construções em mais de 30 cidades e projetadas mais de 100 .

A obra-prima de Brito em construção de esgotos é a rêde da cidade de Santos, que, pelo terreno plano e extenso, em subsolo de areia fluente, se tornou um caso especial, a que êle deu solução original. Ali, Saturnino de Brito criou os tipos de poços de inspeção, os tipos de tanques de lavagem, as plataformas para os coletores de manilhas, as junções radiais e vários outros tipos de obra; ali imaginou e construiu, pela primeira vez, a rêde de esgotos em distritos com os despejos elevados por estações elétricas automáticas. Também resolveu os problemas de drenagem de Santos, criando uma série de canais entre Avenidas, que hoje, com os seus 20 quilômetros de extensão, além da função especial para que foram construídos, representam um motivo de embelezamento e um elemento característico da cidade.

Em Recife, entre 1911 e 1917, Saturnino de Brito construiu os novos serviços de água e esgotos, estabelecendo pela primeira vez no nosso pais o tratamento e a filtração rápida das águas do abastecimento e criando a solução do refôrço das pressões na rêde de água em certas horas do dia, pela adoção original das "bombas de refôrço". 
Em canalizações de rios, para evitar as inundações e sanear extensas zonas urbanas e rurais, tem Saturnino de Brito seus mais interessantes estudos nos Melhoramentos do rio Tieté, em São Paulo, rio Paraiba, no Estado do Rio de Janeiro e nos Melhoramentos da Lagoa Rodrigo de Freitas, no Estado da Guanabara,

Por todos êsses trabalhos o 1? Congresso Brasileiro de Engenharia Sanitária, reunido em 1960 no Rio de Janeiro, em reso lução especial proclamou Saturnino de Brito "Patrono da Engenharia Sanitária Brasileira".

Não devemos terminar esta breve referência a Saturnino de Brito, sem também registrar os nomes dos engenheiros brasileiros que antes de Brito projetaram obras de saneamento no Brasil com diretrizes da Escola Européia: Francisco Bicalho, Alfredo Lisboa e José Pereira Rebouças, além dos estrangeiros Howyan, Fuertes, Sir Douglas Fox e outros.

\section{SANEAMENTO DAS CIDADES}

Em 1922, Saturnino de Brito, apresentando ao $1^{\circ}$ Congresso Brasileiro de Engenharia e Indústria interessante memória sôbre - Saneamento das nossas cidades, perguntava: "Estará a técnica sanitária, em 1922, preparada para dar soluções práticas, econômicas, eficientes, a todos êstes problemas complexos, de acôrdo com as condiçóes naturais e sociais de cada localidade e de cada povo?" E respondia: "Tão grandes foram os progressos realizados em cêrca de 50 anos que podemos responder pela afirmativa".

Atualmente, em 1962, no Brasil, podemos projetar e construir, em todos os detalhes, o abastecimento das cidades, quer se trate de utilizar águas baixas ou águas altas, quer se tenha de perfurar poços profundos ou criar grandes barragens de acumulação; podemos distribuir estas águas econômicamente e construir reservatórios enterrados ou elevados; podemos com materiais do país tratar e filtrar as águas para torná-las potáveis; podemos traçar e construir as rêdes de esgotos e depurar o efluente para que não se torne nocivo às populações; podemos, igualmente, fabricar no país os tubos e peças de ferro fundido, de aço, de grês, de concreto, de cimento-amianto ou de matéria plástica para as nossas rêdes; o cimento, para as barragens e reservatórios, o ferro, para o concreto armado, os hidrômetros, para a medição do fornecimento de água, etc.

Desde 1932 que se vêm fazendo instalações filtrantes nacionais e, depois, estações depuradoras para as águas de esgotos. As bombas para a elevação d'água, bem como motores elétricos, até determinadas capacidades, já são fabricados no Brasil.

O Saneamento das cidades brasileiras teve início no período colonial, quando em 1750 se concluiu o aqueduto de Santa Te- 
resa, no Rio de Janeiro, a primeira obra de valor para o abastecimento d'água de uma cidade brasileira. O esgotamento dos dejetos humanos foi iniciado em 1864, durante o Império, no Rio de Janeiro.

Inúmeros são os exemplos de cidades saneadas em nosso pais por iniciativa da engenharia brasileira e das nossas administrações públicas. Santos e Recife tiveram os antigos esgotos abandonados e substituidos integralmente de acôrdo com a técnica sanitária; os velhos esgotos de Campos e Niterói já estão estudados, em planos completos, para serem melhorados e aumentados.

Podem citar-se como serviços modernos os de São Paulo e quase tôdas as cidades daquele Estado, Belo Horizonte, Juiz de Fora e outras cidades de Minas Gerais, Pôrto Alegre e mais de 30 cidades do Rio Grande do Sul; Salvador, Itabuna, João Pessoa, Campina Grande, Natal, Campo Grande, Vitória, Curitiba, Florianópolis e muitas outras cidades.

$E^{\prime}$ interessante revelar aqui o que Saturnino de Brito esclareceu na citada memória ao Congresso Internacional de Engenharia, em 1922 e que ainda causa surprêsa a muitos: o Rio de Janeiro teve rêde de esgotos em 1864, logo depois de Londres e Hamburgo (1853) e antes de Francfort-sobre-o-Meno (1867), Recife (1873), Berlim (1874), Buenos Aires (1877), Roma (1879), Viena (1883), Nápoles (1893) e Paris (1894).

Isto revela que a monarquia brasileira acompanhava o progresso mundial.

A ação oficial com o fim de sanear as nossas cidades foi, quase sempre, das próprias autoridades da cidade, mas podemos citar verdadeiras campanhas oficiais em prol da execução destas obras, com a criação da Comissão de Saneamento do Estado de São Paulo (1895 a 1898), que tantos e tão bons serviços prestou a várias cidades, da Comissão de Melhoramento Municipais do Estado de Minas Gerais (1910), em que foram adotados os principios, instruções e especificações com que Saturnino de Brito sistematizou os trabalhos de engenharia sanitária no Brasil, da Repartição de Saneamento do Estado do Rio Grande do Sul, em que o Govêrno do Estado em 1920 assumiu a responsabilidade da organização dos projetos de saneamento das cidades e a fiscalização das respectivas obras; e em 1934, o Departamento de Municipalidades do Estado de São Paulo; logo depois, os Departamentos oficiais de Minas, Estado do Rio de Janeiro, Pernambuco e Santa Catarina.

Em 1941 a Comissão de Estudos dos Negócios Estaduais, do Ministério da Justiça, mandou proceder a um inquérito para se ter conhecimento da situação real dos serviços de água e 
esgotos no país. Os resultados, publicados na Revista do Serviço público, de janeiro de 1942, foram incompletos, pois vários Go vernos Estaduais não atenderam ao pedido de dados e outros ainda o fizeram com falta de elementos. Entretanto, pôde se verificar pelos quadros organizados o pequeno número de cidades saneadas até 1940 - 455 com água e 213 com esgotos o que estava a requerer uma ação do Govêrno Brasileiro em bases que foram então indicadas.

Em 1942 foi criado durante a guerra mundial o Serviço Especial de Saúde Pública - o S.E.S.P. - organização oficial iigada ao Instituto de Assuntos Americanos, e que vem prestando reais serviços, projetando e construindo abastecimentos de água na Amazônia, no Vale do Rio Doce e no Nordeste. Atualmente ¿ uma Fundação.

Os Departamentos Nacionais de Obras Contra as Sêcas, de Obras de Saneamento e de Endemias Rurais têm proporcionado realizações muito úteis de obras de saneamento urbano, cujos importes, porém, representam parcela pequena de suas dotações orçamentárias anuais.

Em outubro de 1952 o então Presidente da República, falando no Congresso dos Municipios Brasileiros, reunido em São Vicente, anunciou seu propósito de atender ao saneamento das cidades do interior, fornecendo crédito para essas obras. Foram estas palavras com que apresentou a boa notícia:

"Vivamente impressionado com o fato que, dos mil e novecentos municípios brasileiros, mais de mil e quinhentos não dispóem de serviços de abastecimento de água, o meu govêrno decidiu facilitar aos governos municipais os recursos necessários para atender a essa necessidade imperiosa e elementar de seus habitantes".

Uma Comissão, imediatamente organizada, estudou o problema do crédito para as pequenas cidades, estabelecendo como prioridade para o primeiro ano, dentro do número de 150 cidades, as que não tivessem serviço de água e já possuíssem projeto em bases técnicas.

\section{POLÍTICA DO SANEAMENTO}

O 2. Congresso Brasileiro de Engenharia e Indústria, reunido no Rio de Janeiro em fevereiro de 1946, o IV Congresso de Higiene, realizado no Rio em outubro de 1947, a $1^{\text {: }}$ Conferência Interamericana Regional de Engenharia Sanitária (Rio, junho de 1946), o 1\% Congresso Pan-Americano de Engenharia (Rio, junho de 1949), e o $1^{\circ}$ Congresso dos Municípios Brasi- 
leiros (Petrópolis, abril de 1950), examinaram a politica do saneamento das nossas cidades e concluiram pela necessidade de:

- obrigatoriedade de execução de serviços regulares de água para os núcleos de população de mais de 250 casas ou 1.000 habitantes;

- exploração dêsses serviços pelo Poder Público;

- organização do crédito para essas obras, com a criação de recursos e a formação de um Fundo Nacional de Saneamento, com administração autônoma.

Os professôres de Engenharia Sanitária de tôdas as Escolas de Engenharia e Arquitetura do Brasil, reunidos em Belo Horizonte no III Seminário de Engenharia Sanitária, em novembro de 1958, dirigiram-se ao Sr. Presidente da República pedindo a criação do Conselho Nacional de Saneamento, para orientar e supervisionar uma Campanha Nacional de Saneamento.

No I Congresso Brasileiro de Engenharia Sanitária, reunido no Rio de Janeiro em julho de 1960, foi aprovado pela Comissão Especializada de Água Potável a criação de um Fundo Nacional de Saneamento, constituído pelo menos de 1,5\% da Renda Tributária da União e a administrada por um Conselho Nacional de Saneamento.

Expliquemos com mais detalhes a razão dos três pontos da política de Saneamento Urbano que recolhemos das conclusões dos Congressos referidos.

O limite de 250 casas é para um primeiro plano de serviço regular, com rêde de distribuição de água, pois os núcleos menores terão seu abastecimento com distribuição feita por chafarizes, mesmo em um só ponto central.

A exploração dos serviços de saneamento pelo Poder Público é uma necessidade, pois, em se tratando de organizações de que depende a saúde das populações, não é admissivel ficarem entreques à responsabilidade de emprêsas particulares, que objetivam lucros. Nos Estados Unidos da América esta política se firmou, sendo que nos cem anos decorridos de 1840 a 1939 , os serviços públicos, que eram $36 \%$ do total passaram a $73 \%$, como nos mostra em gráfico o Engineering-News-Record de 9-11-39. No Brasil, de inicio, emprêsas particulares construiram e exploraram serviços de água e de esgotos, mas paulatinamente foram êstes sendo adquiridos pelas administrações públicas. Em 1940 houve uma tentativa de se entregar a emprêsas particulares serviços de saneamento, com as concorrências abertas para as cidades do Rio de Janeiro, Niterói e Salvador. Dêsses 3 serviços só chegou a funcionar, como emprêsa particular, a de Niterói, e assim mesmo, durante poucos anos, fracassando, dêste modo, definitivamente, essa orientação. 
Muito se tem falado da má administração dos Serviços Industriais quando entregues aos Governos, mas a solução de transformá-los em Departamentos Autárquicos tem apresentado magnificos exemplos de recuperação, como os das antigas Repartições e hoje Departamento de Saneamento de Natal, São Paulo, Maceió, Recife, Rio Grande e outros. No Rio de Janeiro, a passagem do Departamento de Ågua para o regime autárquico da SURSAN melhorou consideràvelmente as condições do serviço, como já ocorrera com as do Departamento de Esgotos Sanitários.

Como exemplos de Repartições públicas que mantêm a excelência de seus serviços temos a de Santos, a dos serviços do interior do Rio Grande do Sul mantidos pelo Estado e outros.

Além disto, as obras de saneamento não devem ser executadas pelo regime de empreitada, pois uma vez que condicionam a saúde das populações urbanas, não podem ficar dependentes de lucros dos construtores. Elas devem ser sempre perfeitas e a fiscalização não pode sanar tôdas as faltas, porque numa rêde de esgotos, por exemplo, teria de se exercer constantemente, em cada trecho de coletor e em cada fase da sua construção, o que seria o mesmo trabalho de construí-lo. O mesmo diremos das instalações domiciliárias de esgotos que, se mal executadas e sem a necessária ventilação, poderão trazer para dentro das habitações o gás dos esgotos, e com enormes prejuizos para a saúde dos moradores.

O terceiro ponto é reconhecido como imprescindivel pois conhece-se o fracasso de todos os planos de financiamento de obras de saneamento para as nossas cidades, pela atração de capitais para serviços mais rendosos, pela dificuldade de distribuição pelas localidades necessitadas, pela legislação inaplicável decretada até o presente, pela insuficiênciá dos recursos até agora postos à disposição para êsses serviços e pela natural intromissão do interêsse político partidário.

A criação de um Fundo Nacional de Saneamento com administração autônoma e recursos do orçamento do Govêrno $\mathrm{Fe}$ deral é plenamente justificada, por se tratar de obras diretamente ligadas à saûde pública.

Seria também de justiça reservar para êsse Fundo uma quotaparte da arrecadação dos Institutos de Assistência Social e Companhias de Seguros, porque é preciso fazer voltar à origem, em obras úteis, as enormes quantias retiradas de tôdas as cidades e vilas por essas Instituições, além de ser de interêsse de tais Institutos e companhias a diminuição da taxa de mortalidade nas zonas em que operam, diminuição que as obras de saneamento realizam.

A receita dos Institutos em 1958 atingiu a impressionante cifra de 65 bilhões de cruzeiros. 


\section{ESTUDOS E PLANOS DE FINANCIAMENTO}

Entre os estudos para o financiamento de serviços munici. pais de abastecimento de água o mais completo é o do "Relatório da Comissão incumbida de elaborar o Plano do Govêrno Federal", publicado pelo Departamento de Imprensa Nacional, em 1953. Neste relatório estão reunidos todos os dados necessários e úteis para um reexame dêste assunto tão importante. O financiamento então previsto seria feito até o máximo de 5.000 .000 de cruzeiros por Municipio, garantido por $50 \%$ da quota-parte do impôsto sôbre a renda, devida a cada Municipio.

O folheto "Abastecimento d'água para pequenas comunidades", de Walter R. Ribeiro Sanches, publicado pelo Serviço de Documentação do D.A.S.P. em 1957, aborda também o problema, comenta o Plano Federal e apresenta um Plano para a distribuição das verbas já consignadas no Orçamento da República.

A publicação "Financiamento dos Serviços Municipais de Abastecimento de Ågua", do Conselho de Desenvolvimento feita em 1957, é uma documentação complementar ao Decreto número 41.466, de 3 de maio de 1957 e examina os dados necessários para a concessão de empréstimos ao Municípios.

\section{LEIS E DECRETOS}

A Lei n².134, de 14 de dezembro de 1953, assegurou o financiamento a longo prazo de Serviços Públicos Municipais. Esta lei limitou a concessão dos empréstimos aos Municipios com renda inferior a $\operatorname{Cr} \$ 15.000 .000,00$ (quinze milhões de cruzeiros), a prazos máximos de 20 anos, para vários serviços municipais, sendo as operaçóes de crédito concedidas pelas Caixas Econômicas Federais nos Estados até 30\% dos depósitos, pelos Institutos e Caixas de Aposentadoria até $20 \%$ do que arrecadam em cada Estado e pela Caixa Econômica do Distrito Federal, para todo o país, até $15 \%$ dos seus depósitos. Estes empréstimos teriam suas amortizações e juros garantidos pela quota que coubesse ao municipio na distribuição do impôsto único sôbre a energia elétrica e pela metade da quota de que trata o art. 15 , parágrafo $4 \%$, da Constituição Federal. Esta lei foi regulamentada pelo Decreto n 35.064 , de 13-2-54.

A Lei $n^{\circ} 2.599$, de 13 de setembro de 1955, dispõe sôbre - "Plano Geral de Aproveitamento Econômico do Vale do São Francisco" e traça plano para cooperação com os Municipios do Vale para a instalação de serviço de abastecimento de água potável. O Decreto $\mathrm{n}^{\circ} 38.969$, de 4 de abril de 1956, regulamenta o artigo $8^{\circ}$ desta lei.

O Decreto $n^{\circ} 40.444$ de 30 de novembro de 1956, aprovou - Regulamento expedido em virtude da Lei $n^{\circ} 2.814$, de 6 de 
julho de 1956, que dispõe sôbre a concessão de auxílio aos Mu nicipios situados no Poligono das Sêcas para instalação de ser viços públicos de abastecimento d'água.

A Lei $n^{2} 2.973$ de 26 de novembro de 1956, estabelece no artigo 32: - "Caberá ao Banco Nacional de Desenvolvimento Econômico atender também às propostas de empréstimos de Prefeituras Municipais, segundo as normas gerais da Lei $n^{?} 2.134$ de 14 de dezembro de 1953.

O Projeto de Lei $n^{\circ}$ 3.462-53, de autoria do Deputado Raymundo Padilha, criaria o "Fundo de Emergência Municipal", para melhoramentos urbanos em cidades de menos de 50.000 habitantes.

O Projeto de Lei $\mathrm{n}^{9} 1.473-56$ autorizava o Poder Executivo a financiar o estudo e a construção de sistemas públicos de abastecimento de água e o Projeto de Lei n 1.508 de 1956, apresentado pelos Deputados Oliveira Franco e Pontes Vieira, dispunha sôbre a forma do serviço de abastecimento de água potável nas cidades.

Como se vê, há vários estudos, vários planos e várias leis, sôbre o financiamento de serviços de água para as cidades brasileiras, mas até o presente nada de prático e eficiente foi realizado no que diz respeito a plano nacional.

Para a garantia de execução de qualquer plano de saneamento das cidades é necessário realizar o entrosamento, a cooperação, entre os Governos Municipais, Estaduais e Federal.

Qualquer plano deve ser feito com garantias para ser executado automàticamente, sem perigo de paralisação por programas de economia dos Governos, ou por retenção de verbas, ou por outras limitações burocráticas ou de política.

\section{RECURSOS}

Há no Orçamento da República verbas para atender a serviços de saneamento em vários setores do pais.

Em 1960 foram consignados para abastecimento d'água de cidades 2.323 milhões de cruzeiros, assim distribuídos:

Comissão do Vale do São Francisco ..........

Superintendência de Valorização da Amazôña.....

Poligono das Sêcas (D.N.O.C.S.) ...........

Outras áreas, incluindo a Comissão da Faixa de Fronteiras $\ldots \ldots \ldots \ldots \ldots \ldots \ldots \ldots \ldots \ldots \ldots \ldots \ldots \ldots$

Esta importância no Orçamento de 1953 era de 170,1 milhões de cruzeiros, no de 1954 era de 215,8 e no de 1955 de 246,7 .

Os recursos para um plano de financiamento de estudos e obras para o abastecimento de água para as pequenas cidades do 
pais estão, pois, indicados nas leis existentes e nos Orçamentos da República, podendo os seus valores serem aumentados.

Encontra-se transitando no Congresso Nacional um projeto de lei transformando em autarquia o Departamento Nacional de Obras de Saneamento e possibilitando que seja também executor de obras de saneamento urbano, como de há muito já é de saneamento rural. Torna-se necessário, entretanto, que se disponha em lei que possa realizar tais obras em convênio com os Estados ou Prefeituras que disponham de Serviços ou Departamentos aparelhados para tal, porque o nosso sistema de Govêrno é federativo e o D.N.O.C.S. deve de preferência centralizar apenas diretrizes e fiscalização, deixando a execução à iniciativa e encargo dos órgãos locais.

Há Estados, como o do Rio Grande do Norte e o de Pernambuco, que já têm estipuladas em suas Constituições verbas para êsses serviços.

Está faltando, portanto, o modo de encaminhar recursos e empréstimos e de fiscalizar as obras, sem perdas de tempo e sem exageros burocráticos.

No momento, os grandes auxilios norte-americanos, provenientes do Acôrdo do Trigo e da Aliança para o Progresso, fizeram surgir uma nova esperança para a solução dos problemas do saneamento de cidades brasileiras. Estão aprovados os empréstimos do Banco Internacional de Desenvolvimento para $7 \mathrm{ca}-$ pitais do Norte e várias cidades do Nordeste.

\section{MELHORIA DE SAÚDE}

A primeira necessidade para o homem como lembra W. M. C. Groeniger, é o ar, porque sem êle a vida se escoa em poucos minutos: a segunda, a água porque sem ela não se vive mais do que alguns dias. $E^{\prime}$ um forte argumento para ressaltar a importância da água, sem a qual o individuo e as populações não podem viver. Sem serviços organizados com água de qualidade garantida, não se desenvolvem as cidades e a saúde pública periga.

E' de utilidade salientar que a realização de obras de saneamento não representa apenas confôrto, porém é remuneradora para a coletividade, pela economia de vidas que determina e pelas doenças evitáveis que impede.

A morte prematura e a incidência mórbida constituem perdas econômicas, em virtude da redução de potencial de produção que ocasionam, quer pela subtração direta do elemento humano, quer pela diminuição da capacidade de trabalho, quer pelo acréscimo das despesas nos cuidados médicos e hospitalares.

O cotejo das taxas de mortalidade antes e depois das obras de saneamento em muitas cidades, mostra o que êsses serviços 
representam em vidas poupadas. No Rio Grande do Sul a com paração entre as taxas de mortalidade em cidades com e sem saneamento, comprovou claramente o afirmado. Têm-se, assim:

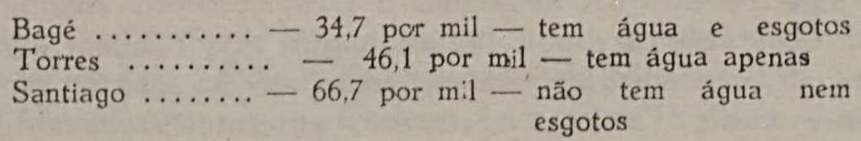

A economia em capital humano será ainda maior que em Bagé quando se estendam os serviços de água e esgotos a tôda a cidade e se criem hábitos de educação sanitária, dado que em cidades assim totalmente saneadas tem-se observado o decréscimo da taxa de mortalidade para 15 por mil habitantes.

Sabe-se que as vítimas de doenças de origem hidrica têm a extensão de sua vida reduzida de $25 \%$ em média.

A incidência de doenças intestinais nas cidades desprovidas de serviços de água é por vêzes $90 \%$ sôbre a população. Cêrca de $35 \%$ dos óbitos registrados em muitas cidades, devem-se a doenças intestinais.

Nas cidades com serviços regulares de saneamento, observei nos inquéritos procedidos em 1941 e 1949 que apenas 65\% de casas são ligadas à rêde de água e $46 \%$ à de esgotos. Atualmente no Rio de Janeiro e em São Paulo estas percentagens são bem inferiores.

Nos Estados Unidos, 82 milhões de habitantes, isto é, $50 \%$ da população total ou $85 \%$ da população urbana, são servidos de água canalizada, enquanto em nosso país a população servida (2.281.000 ligações) é da ordem de $16 \%$ da população total ou $35 \%$ da população urbana. As ligações à rêde de esgotos são pràticamente a metade das de água (1.266.000).

\section{OBSERVAÇÕES FINAIS}

Pode-se, agora, imaginar o contingente de elementos humanos economizado com a instalação de serviços de saneamento nas nossas cidades e pode-se ter uma visão do enorme trabalho que aos engenheiros está destinado neste setor importante da engenharia brasileira.

A parte técnica humana para essas obras não é de fácil recrutamento, pois há outros setores de mais acessivel exploração, por se desenvolverem entre as comodidades de vida das grandes cidades, como a construção de edifícios, cálculo de concreto armado, etc., que atraem os moços nos dias de hoje, como mostra, por exemplo, a discriminação entre os formados nas diversas especializações da Escola Nacional de Engenharia. Eis por que, para garantir o futuro do nosso país, se faz necessária uma 
verdadeira campanha, visto que serão indispensáveis muitos engenheiros sanitários, moços que se possam dedicar a êste ramo, que estejam decididos a passar os primeiros anos de sua vida técnica em cidades pequenas, no interior, sem as facilidades dos grandes centros, e que tenham a convicção de estar realizando uma grande obra humana.

Foi por isto que Saturnino de Brito não se limitou a nos deixar apenas uma técnica de projetar e construir obras de água e esgotos para as cidades, e em deixar tipos de obras com os quais podemos simplificar e tornar mais econômicas as construções do saneamento, mas nos ensinou sobretudo a razão de ser do devotamento que se deve exigir do engenheiro que se dedica a esta espécie de obras, mostrando sempre que delas provém a melhoria da saúde das populações, a vida mais longa do nosso homem e, portanto, a felicidade da Pátria. E' esta a mentalidade que êle criou entre os seus engenheiros, é o ideal que pregou e que deverá conduzir o engenheiro sanitário na campanha pelo saneamento das nossas cidades.

Porém, não é apenas na execução do saneamento das cidades que se deve manter uma mentalidade entre os engenheiros, mentalidade de idealismo; - esta é necessária em todos os setores e é uma satisfação verificar que ela existe ainda neste mundo conturbado e imediatista.

Na conferência citada, no início desta palestra, do Presidente da Associação de Engenheiros Civis de França, comenta êste que são erradas as conclusões de que se vive numa época des, provida de "élan" espiritual e que os valores humanos estejam só ao serviço do materialismo; e diz que o ser humano conhece ainda as grandes alegrias do entusiasmo e do devotamento, citando os casos de dois engenheiros cujo esfôrço pessoal êle seguiu. Aqui bastará referir um dêles, que vou tentar reproduzir. A França efetuou três ensaios nucleares, sem um fracasso, apesar da falta absoluta de informações que os países mais avançados nesses estudos poderiam ter fornecido. Os engenheiros franceses tiveram de tomar o problema desde o inicio. Entre os estudos, o relativo à escorva necessitava, antes mesmo de tôda experimentação, uma série interminável de cálculos resultantes do estabelecimento e solução de funções especiais e variadas. O engenheiro encarregado dêste trabalho foi acometido de poliomielite e necessitou recurso à respiração artificial. Ele teria tôdas as razões válidas para interromper os estudos que fazia, mas, transportado para uma clínica especial, submetido a tratamentos rigorosos, êle não parou os seus cálculos.

Os atos mais sérios tomam, quase sempre, o aspecto de uma competição e isso impunha ao engenheiro em causa a obrigação de terminar șua mișsão numa data determinada. Elle pôr de reș. 
peitar essa data, mas não se sabe se, com êsse esfôrço, êle conseguiu dominar a moléstia. Nenhuma satisfação material, nenhuma ambição pessoal teriam podido galvanizá-lo a êste ponto; só a grandeza de sua tarefa o animou e o levou ao término da mesma.

E' o ideal necessário em todos os trabalhos, em todos os setores, o que fêz o poeta de "Terra dos Homens" exclamar:

"E Quem luta apenas na esperança de bens materiais, não colhe nada que valha a pena viver". 